\title{
Comparison of supercritical fluid and hexane extraction methods in extracting kenaf (hibiscus cannabinus) seed oil lipids.
}

\begin{abstract}
The objective of this study was to investigate and compare fatty acids, tocopherols and sterols of kenaf seed oil extracted by supercritical carbon dioxide and traditional solvent methods. Fatty acids, tocopherols and sterols were determined in the extracted oils as functions of the pressure (400 bar, 600 bar), temperature $\left(40{ }^{\circ} \mathrm{C}, 80{ }^{\circ} \mathrm{C}\right)$ and $\mathrm{CO} 2$ flow rate $(25 \mathrm{~g} / \mathrm{min})$ using a 1-L extraction vessel. Gas chromatography was used to characterize fatty acids and sterols of the obtained oils while tocopherols were quantified by HPLC. No differences were found in the fatty acid compositions of the various oil extracts and the main components were found to be linoleic (38\%), oleic (35\%), palmitic (20\%) and stearic acid (3\%). Extraction of tocopherols using high pressure $\left(600 \mathrm{bar} / 40{ }^{\circ} \mathrm{C}, 600 \mathrm{bar} / 80{ }^{\circ} \mathrm{C}\right)$ gave higher total tocopherols ( 88.20 and $85.57 \mathrm{mg} / 100 \mathrm{~g}$ oil, respectively) when compared with hexane extraction which gave yield of $62.38 \mathrm{mg} / 100 \mathrm{~g}$ oil. Extraction of kenaf seed oil using supercritical fluid extraction at high temperature $\left(80^{\circ} \mathrm{C}\right)$ gave higher amounts of sterols when compared with hexane extraction.
\end{abstract}

Keyword: Fatty acid; Hexane extraction; Kenaf seed; Sterols; Supercritical fluid extraction; Tocopherol. 